\title{
Human papillomavirus vaccine risk and reality
}

Published at www.cmaj.ca on Sept. 1, 2008.

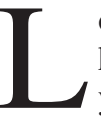
oudly voiced concerns greeted Canada's school-based human papillomavirus (HPV) vaccine programs last year. This was particularly the case in Ontario, where vaccine uptake was only about $50 \%$, a sharp contrast to over $80 \%$ uptake in Nova Scotia and Australia. In comparison, uptake of the hepatitis B vaccine is over $90 \%$ in schoolbased programs across Canada. So why did HPV vaccine uptake fall below expectations, given that the goal is prevention of cervical cancer, a potentially fatal disease?

Cassels ${ }^{1}$ characterized the vaccine debate as the "just do it" camp, which focuses on averting potential cervical cancer deaths, versus the "what's the hurry" camp, which focuses on residual unknowns such as costs, effectiveness and safety. This debate has been valuable for those who followed it attentively, but some parents and potential vaccine recipients who chose not to participate in the program may have only heard fragments of the discourse.

There are lessons to be learned here for European countries and other Canadian provinces that are poised to launch HPV vaccine programs. Ensuring trust in any vaccine program requires anticipating and proactively addressing concerns of parents and potential vaccine recipients, especially those in the "what's the hurry" camp. Emphasis and data on vaccine safety, vaccine benefits and disease risk are crucial.

Although all new vaccines are studied for effectiveness and safety before licensure, vaccine trial participants often do not represent the general population. And although trials may enrol several thousand participants, this is often too few to detect rare serious adverse effects. This raises legitimate safety concerns among parents and potential recipients.

In this issue, Brotherton and colleagues ${ }^{2}$ provide compelling evidence that the HPV vaccine is remarkably safe. In Australia, the only serious adverse events noted with careful follow-up of over 260000 vaccine doses were very rare cases of anaphylaxis ( 2.6 events per 100000 doses). There were no cases of anaphylactic shock. All of the girls recovered completely, usually rapidly after receiving epinephrine. In a related commentary, Halsey ${ }^{3}$ provides further support for the rareness of anaphylaxis and other serious adverse events following administration of millions of doses of this vaccine. These data should provide reassurance to parents and potential recipients who have called for more evidence of the vaccine's safety.

The study by Brotherton and colleagues gives the Canadian public health community an excellent opportunity to restart public discussions about the safety of the HPV vaccine, the precautions taken to mitigate risks if anaphylaxis occurs, and the care taken in surveillance for adverse events following vaccination. ${ }^{4}$ These school-based vaccine programs require vaccine providers to have the training and equipment needed to manage anaphylaxis and to observe recipients for 15 minutes after vaccination; these are basic requirements for providing vaccination in any setting. ${ }^{4}$

Public health campaigns must address the fact that parents and potential vaccine recipients see remote health concerns as more easy to ignore than those close at hand. Cervical cancer may seem a remote risk for a teenager, but in Canada an estimated 1300 women will be diagnosed with cervical cancer this year and 380 will die. ${ }^{5}$ This risk remains despite decades of public health campaigns about the importance of regular screening.

Delaying immunization until a young woman is sexually active may seem a credible alternative, but it is not. HPV infection can occur with the first sexual intercourse, and half of Canada's young women become sexually active by age 16 . Adolescent behavioural risk factors are inadequate predictors of future infection with vaccine type HPV. ${ }^{6}$

Ideally, high rates of HPV immunization would reduce cervical cancer risk for unvaccinated as well as vaccinated women via herd immunity. At present, this is unlikely to happen because both males and females would need to be immunized. Canada and other industrialized countries (except for Australia) have only approved vaccination for females thus far, because studies involving males have not been completed. Hence, for now, only immunized women will be protected.

By publishing these vaccine safety data, CMAJ continues to add to the HPV vaccine discourse. Now it is up to public health and other practitioners to listen carefully and respond to the public's concerns. Respecting every woman's right to decide for herself about the HPV vaccine includes ensuring that this decision is based on a balanced and factual perspective of the competing risks, rather than on ignorance or irrational fears.

\section{Noni MacDonald MD MSc \\ Section Editor, Public Health \\ Matthew B. Stanbrook MD PhD \\ Deputy Editor, Scientific \\ Paul C. Hébert MD MHSc \\ Editor-in-Chief \\ CMAJ \\ With the Editorial-Writing Team (Rajendra Kale MD, Barbara Sibbald BJ, Ken Flegel MDCM MSc and Amir Attaran LLB DPhil)}

Competing interests: See www.cmaj.ca/misc/edboard.shtml.

\section{REFERENCES}

1. Cassels AK. Vaccination against human papilloma virus [letter]. CMAJ 2007;177: 1526.

2. Brotherton JML, Gold MS, Kemp AS, et al. Anaphylaxis following quadrivalent human papillomavirus vaccination. CMAJ 2008;179:525-33.

3. Halsey NA. The human papillomavirus vaccine and risk of anaphylaxis. CMAJ 2008;179:509-10.

4. Public Health Agency of Canada. Canadian Immunization Guide. 7th ed. Ottawa (ON): The Agency; 2006. Available: www.phac-aspc.gc.ca/publicat/cig-gci/indexeng.php (accessed 2008 Aug 5)

5. Canadian Cancer Society. Canadian Cancer Statistics. Toronto (ON): The Society; 2008. Available: www.cancer.ca/ccs/internet/standard/0,3182,3172_14279 langId-en,00.html (accessed 2008 Aug 5).

6. Dempsey AF, Gebremariam A, Koutsky L, et al. Behavior in early adolescence and risk of human papillomavirus infection as a young adult: results from a population-based study. Pediatrics 2008;122:1-7. 